Case

Report

\title{
Iatrogenic Aortic Valve Perforation after Ventricular Septal Defect Repair
}

Chonglei Ren, MD, Shengli Jiang, MD, Mingyan Wang, MD, Yao Wang, MD, and Changqing Gao, MD

\begin{abstract}
Iatrogenic aortic valve (AV) perforation during non-aortic cardiac operations is a rare complication. The suture-related inadvertent injury to an AV leaflet can produce leaflet perforation with aortic regurgitation after ventricular septal defect repair (VSDR). We report three consecutive patients who had iatrogenic aortic leaflet perforation during VSDR in other hospitals and referred to our hospital for reoperation. In all three cases, the perforated AV leaflets were preserved and repaired by autologous pericardial patch or direct local closure.
\end{abstract}

Keywords: iatrogenic aortic valve perforation, ventricular septal defect repair, surgical complication

\section{Introduction}

Iatrogenic valvular regurgitation has been reported after different cardiac procedures as a result of leaflet perforation or entrapment. ${ }^{1,2)}$ Iatrogenic aortic valve (AV) perforation during non-aortic cardiac operations is a rare complication. The suture-related inadvertent injury to an $\mathrm{AV}$ leaflet can produce leaflet perforation with aortic regurgitation (AR) after ventricular septal defect repair (VSDR). ${ }^{3,4)}$ This injury results from the immediate anatomic vicinity of the AV, especially the right coronary leaflet and noncoronary leaflet. New onset of AR after a repair procedure on ventricular septal defect (VSD) can be the direct consequence of aortic leaflet perforation caused by the stitches. This risk may be greater with inexperienced surgeons in lower-level hospitals. In this report, we described three consecutive

Department of Cardiovascular Surgery of Chinese PLA General Hospital, Institute of Cardiac Surgery, Beijing, China

Received: February 13, 2017; Accepted: May 2, 2017

Corresponding author: Shengli Jiang, MD. Department of Cardiovascular Surgery of Chinese PLA General Hospital, No. 28 Fu Xing Road, Beijing 100853, China

Email: renchl70@sina.com

(C)2018 The Editorial Committee of Annals of Thoracic and Cardiovascular Surgery. All rights reserved. patients who suffered AR after VSDR. In all the cases, AV perforation was repaired by autologous pericardial patch or direct local closure.

\section{Case Report}

From 2013 to 2015, three patients (Table 1) who presented with a new onset of AR after VSDR in other hospitals were referred to our hospital. All three patients successfully underwent reoperation in our institution. The interval between VSDR and the reoperation for repair of aortic perforation ranged from 7 to 12 years. All three patients had simple closure of a membranous VSD previously in other hospitals. None of these patients had a history of endocarditis or chest trauma. Physical examination revealed a diastolic murmur over the aortic valvular area. Chest X-ray showed an enlarged cardiac silhouette and a normal pattern of pulmonary vascularity. Electrocardiogram revealed sinus rhythm with/without complete right bundle branch block. Transthoracic echocardiography (TTE) showed AV perforation in the noncoronary leaflet near the annulars. The length of the leaflet tear ranged from 4 to $6 \mathrm{~mm}$. The left ventricles were dilated with the left ventricular end-systolic dimension index (LVESDI) $>25 \mathrm{~mm} / \mathrm{m}^{2}$ (Table 2). The left ventricular (LV) systolic functions were normal in all three patients. 
Table 1 Clinical, echocardiographic, and operative data

\begin{tabular}{|c|c|c|c|c|c|c|c|c|c|}
\hline $\begin{array}{l}\text { Patient } \\
\text { no. }\end{array}$ & Age & Sex & $\begin{array}{c}\text { AR } \\
\text { history }\end{array}$ & $\begin{array}{c}\text { Interoperative } \\
\text { interval }\end{array}$ & $\begin{array}{l}\text { Perforation } \\
\text { size in NCC }\end{array}$ & $\begin{array}{c}\text { AR } \\
\text { degree }\end{array}$ & $\begin{array}{l}\text { LVESDI } \\
\left(\mathrm{mm} / \mathrm{m}^{2}\right)\end{array}$ & $\begin{array}{c}\mathrm{AV} \\
\text { operation }\end{array}$ & Outcome \\
\hline 1 & $10 \mathrm{y}$ & $\mathrm{F}$ & $0.5 \mathrm{y}$ & $7 y$ & $\begin{array}{c}4 \mathrm{~mm} \\
\text { perforation }\end{array}$ & Severe & 29.6 & $\begin{array}{l}\text { Interrupted } \\
\text { suture }\end{array}$ & $\begin{array}{c}\text { No residual } \\
\text { AR }\end{array}$ \\
\hline 2 & $13 \mathrm{y}$ & $\mathrm{F}$ & $10 \mathrm{y}$ & $11 \mathrm{y}$ & $\begin{array}{c}4 \mathrm{~mm} \\
\text { perforation }\end{array}$ & Severe & 27.1 & $\begin{array}{l}\text { Interrupted } \\
\text { suture }\end{array}$ & $\begin{array}{c}\text { No residual } \\
\text { AR }\end{array}$ \\
\hline 3 & $16 \mathrm{y}$ & $\mathrm{F}$ & $1 \mathrm{y}$ & $12 \mathrm{y}$ & $\begin{array}{c}6 \mathrm{~mm} \\
\text { perforation }\end{array}$ & Severe & 26.8 & $\begin{array}{l}\text { Pericardial } \\
\text { patch }\end{array}$ & Trivial AR \\
\hline
\end{tabular}

AR: aortic regurgitation; F: female; AV: aortic valve; LVESDI: left ventricular end-systolic dimension index; NCC: noncoronary cusp

Table 2 Supplementary echocardiographic data

\begin{tabular}{cccccc}
\hline $\begin{array}{l}\text { Patient } \\
\text { no. }\end{array}$ & $\begin{array}{c}\text { LVEDD } \\
(\mathrm{mm})\end{array}$ & $\begin{array}{c}\text { LVESD } \\
(\mathrm{mm})\end{array}$ & $\begin{array}{c}\text { LVEF } \\
(\%)\end{array}$ & $\begin{array}{c}\text { LVESDI } \\
\left(\mathrm{mm} / \mathrm{m}^{2}\right)\end{array}$ & $\begin{array}{c}\text { BSA } \\
\left(\mathrm{m}^{2}\right)\end{array}$ \\
\hline 1 & 56 & 32 & 60 & 29.6 & 1.08 \\
2 & 58 & 38 & 56 & 27.1 & 1.40 \\
3 & 58 & 37 & 58 & 26.8 & 1.38 \\
\hline
\end{tabular}

LVEDD: left ventricular end-diastolic dimension; LVESD: left ventricular end-systolic dimension; LVEF: left ventricular ejection fraction; LVESDI: left ventricular end-systolic dimension index; BSA: body surface area

All the operations required standard cardiopulmonary bypass through median sternotomy. The AV was inspected through a standard aortotomy incision. In all the cases, redo operation revealed that the AR resulted from perforation of the noncoronary leaflet was close to the annulus (Fig. 1). The length of the leaflet tear ranged from 4 to $6 \mathrm{~mm}$. AV repair was attempted in all cases. The first and second patients with a $4 \mathrm{~mm}$ perforation were closed with two interrupted 5-0 Prolene sutures (Ethicon US, LLC., Somerville, NJ, USA) with pericardial pledgets to buttress the suture (Fig. 2). The third case with AV perforation of $6 \mathrm{~mm}$ in length could not be directly sutured. To cover the tear, an autologous pericardial patch was trimmed according to the size of the perforation, and sutured with a 6-0 Prolene continuous suture (Ethicon US, LLC., Somerville, NJ, USA).

All patients recovered from the redo operation uneventfully. On discharge, two patients had competent $\mathrm{AVs}$ without regurgitation, and the other patient had trivial AR. During the follow-up, TTE performed at 1 year showed no significant AR in all three patients, and normal left ventricular dimensions were restored.

\section{Discussion}

Iatrogenic $\mathrm{AV}$ perforation following cardiac operations is a rarely reported complication. ${ }^{1,2)} \mathrm{AV}$ perforation after

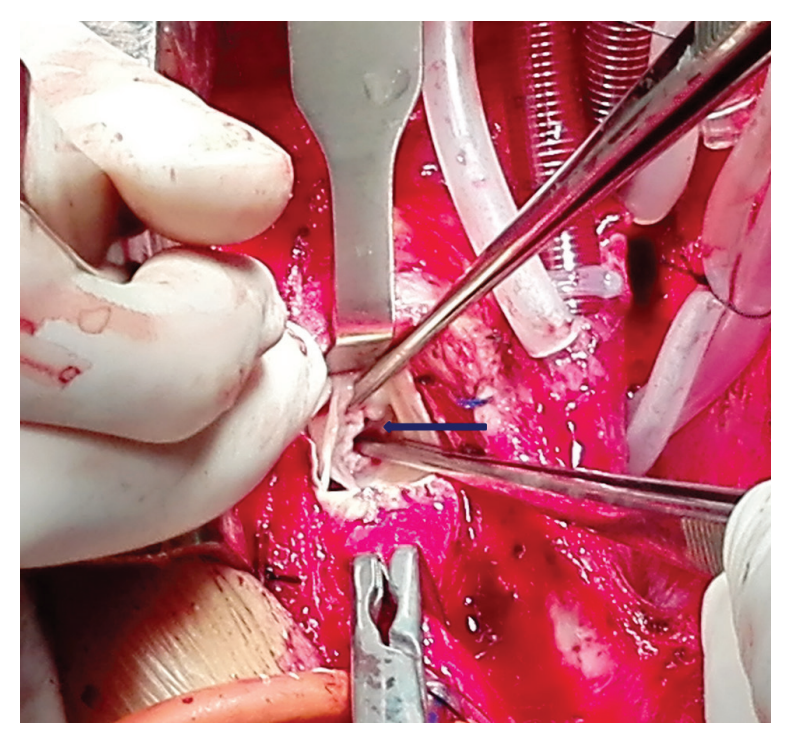

Fig. 1 The first patient with a $4 \mathrm{~mm}$ perforation in the noncoronary leaflet (arrow indicates the perforation).

VSDR is rare and mostly studied as the case reports. ${ }^{4-7)}$ We report three consecutive patients who suffered significant aortic leaflet injury in the noncoronary leaflet during VSDR procedure and referred for reoperation in our institution.

Diagnosis of AV perforation due to VSDR is not difficult. Iatrogenic AV leaflet perforation should be suspected when a new AR murmur develops after VSDR operations. New onset of AR or deterioration of existing AR after a VSDR procedure can be diagnosed by TTE, ${ }^{1)}$ and if necessary, it can be further examined by transesophageal echocardiography. ${ }^{3,8)}$ Moreover, meticulous echocardiographic examination not only detects valve insufficiency, but also allows recognition of the mechanism and severity of the insufficiency. The echocardiographic manifestations included echo-dropout in the AV leaflet with or without an eccentric jet of AR in the AV leaflet close to the aortic root. ${ }^{1)}$ None of the three patients had significant AR before the first operation for VSD, 


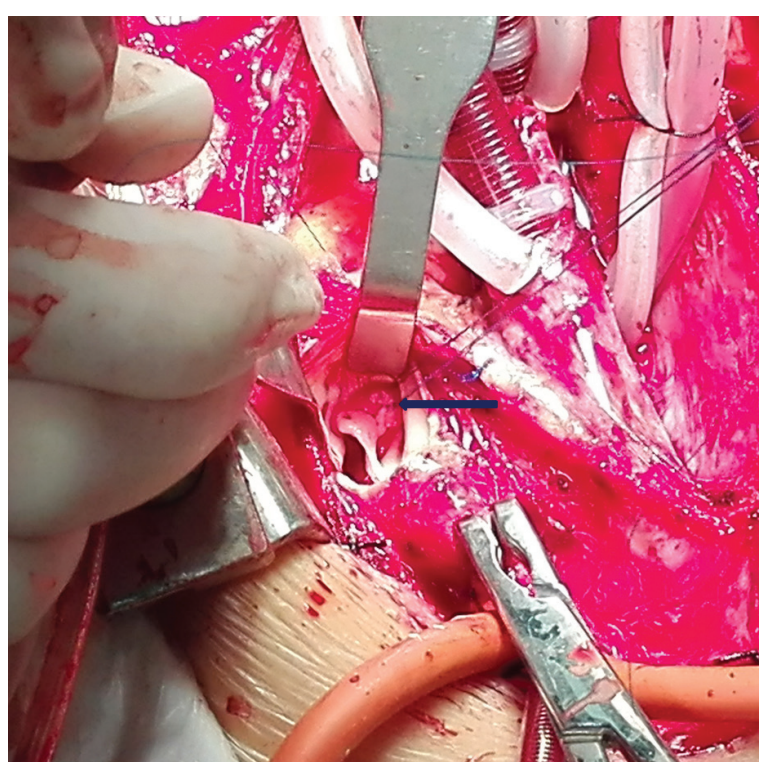

Fig. 2 The perforation was sutured with pericardial felt pledget (arrow indicates pericardial felt pledget).

and a new AR was observed after VSDR. So iatrogenic AV perforation was diagnosed by history of previous VSDR procedure and the typical echocardiographic findings in the three patients.

Proper management of the iatrogenic complications by the surgeon is important. ${ }^{4}$ ) The increased awareness of the complication results in avoidance of adverse surgical results while performing VSD repair, and improves the ability to repair iatrogenic leaflet perforation. $\mathrm{AV}$ repair is most commonly performed in patients with severe AR due to AV leaflet perforation. The repair methods include direct local closure and patch repair of the leaflet perforation using autologous pericardium. In all cases presented, valve repair was performed, leading to excellent functional and clinical outcomes. This finding is in agreement with other reports demonstrating that repair of aortic leaflet perforation offers the satisfactory results. ${ }^{9,10)}$ This report consequently demonstrates that $\mathrm{AV}$ preservation should be striven for as the procedure of choice.

Even if AV injury during a VSDR procedure is a rare complication, any new AR should alert the surgeon to be aware of this deterioration. More attention should be paid to the rare complications, and proper imaging techniques employed for diagnosis so as to intervene as soon as possible. ${ }^{4}$ Continuous monitoring and documentation of $\mathrm{AV}$ function after a VSDR procedure is mandatory. In mild or moderate AR, careful observation is justified, while bearing in mind the risk and extent of redo operation. The iatrogenic AV leaflet injury may present after a long time with progressive AR in majority of the patients. As time passed, the patient's heart gradually dilated, and reoperation to repair the $\mathrm{AV}$ perforation was inevitable. When AR is severe and heart enlargement is detected on TTE after the VSDR operation, this injury can necessitate redo-operative repair of the aortic leaflet. Otherwise, the relevant AR can lead to impairment of left ventricular function over time, thereby placing the patient at additional risk. The first and third patients were found to have significant $\mathrm{AR}$ at 6 , and 11 years postoperatively, whose left ventricle was significantly dilated with the LVESDI $>25 \mathrm{~mm} / \mathrm{m}^{2}$ although the patients did not have significant symptoms. It is class IIa recommendation for AV replacement in 2014 American Heart Association (AHA)/American College of Cardiology (ACC) valvular heart disease guideline, so redo operation was indicated.

From 2013 to 2015 at our center, we admitted three patients who had suffered from an iatrogenic AV injury after VSDR. We believe that the incidence of iatrogenic AR after a VSDR procedure may be higher than previously reported. So we suspect that there is still a fraction of patients who have mild AR due to iatrogenic leaflet defect do not receive treatment upon proper evaluation. The AR may be underdiagnosed or remain undetected on discharge, and very small perforations can enlarge over time. As the first operations for VSD in the three patients were performed in other hospitals, the lack of longitudinal observation of AR was the main flaw in our report.

\section{Conclusion}

Aortic leaflet injury is an infrequent but severe complication of VSDR. Because of the serious consequences, it should be mentioned in the informed consent process. We report three consecutive patients who suffered AR after VSDR. In all cases, the AV perforations were repaired by autologous pericardial patch or direct local closure. The valve preserving repair of the injury is feasible with excellent clinical and functional midterm results.

\section{Disclosure Statement}

The authors declare that they have no conflicts of interest.

\section{Ethics Approval and Consent to Participate}

The clinical study of the above-mentioned case report was approved by the Ethics Committee for Clinical 
Research of Chinese PLA General Hospital concerning the publication of this manuscript and any accompanying images.

Written informed consent was obtained from the patients for publication of this case report and any accompanying images.

\section{References}

1) Hill AC, Bansal RC, Razzouk AJ, et al. Echocardiographic recognition of iatrogenic aortic valve leaflet perforation. Ann Thorac Surg 1997; 64: 684-9.

2) Kolakalapudi P, Chaudhry S, Omar B. Iatrogenic aortic insufficiency following mitral valve replacement: case report and review of the literature. J Clin Med Res 2015; 7: 485-9.

3) Dreyfus J, Feldman LJ, Lepage L, et al. Iatrogenic aortic valve perforation assessed using three-dimensional transoesophageal echocardiography. Arch Cardiovasc Dis 2011; 104: 486-7.

4) Woo JJ, Koh YY, Chang KS, et al. A case of iatrogenic aortic valve leaflet perforation after closure of a ventricular septal defect. Int J Cardiovasc Imaging 2010; 26 Suppl 1: 169-72.

5) Wada J, Yokoyama M, Imai Y, et al. Hemolysis due to aortic insufficiency following closure of ventricular septal defect. Int Surg 1979; 64: 53-6.

6) Zhang T, Jiang S, Wang Y, et al. Surgery on a patient with iatrogenic aortic valve leaflet perforation after repair of a congenital ventricular septal defect. Heart Surg Forum 2013; 16: E103-6.

7) Sabzi F, Teimouri H, Moloodi A. Subacute aortic regurgitation as a rare presentation of iatrogenic aortic valve leaflet perforation. Acta Medica Iranica 2009; 47: 499-501.

8) Ballal RS, Mahan EF, Nanda NC, et al. Aortic and mitral valve perforation: diagnosis by transesophageal echocardiography and Doppler color flow imaging. Am Heart J 1991; 121: 214-7.

9) Minakata K, Schaff HV, Zehr KJ, et al. Is repair of aortic valve regurgitation a safe alternative to valve replacement? J Thorac Cardiovasc Surg 2004; 127: 645-53.

10) Mosala Nezhad Z, de Kerchove L, Hechadi J, et al. Aortic valve repair with patch in non-rheumatic disease: indication, techniques and durability. Eur J Cardiothorac Surg 2014; 46: 997-1005; discussion 1005. 